\title{
Erectile Dysfunction among Diabetic Patients at Parirenyatwa Group of Hospitals in Zimbabwe
}

\author{
Article by Pasipanodya Ian Machingura ${ }^{1}$, Vasco Chikwasha ${ }^{2}$ \\ ${ }^{1}$ Department of Medical Laboratory Sciences, University of Zimbabwe College of Health \\ Sciences \\ ${ }^{2}$ Department of Community Medicine, University of Zimbabwe College of Health Sciences \\ E-mail: imachingura@yahoo.co.uk ${ }^{l}$
}

\begin{abstract}
Erectile dysfunction is a major problem amongst diabetes mellitus patients. However sexual problems are not usually discussed with doctors due to embarrassment and lack of understanding of the condition thus the patients suffer silently. The study sought to determinate the prevalence of erectile dysfunction and associated factors amongst male diabetes mellitus patients attending the outpatient clinic at Parirenyatwa group of hospitals.

Adult male diabetic patients who consented to participate in the study had a questionnaire administered on them to collect demographic data and an International Index of Erectile Function (IIEF5) Questionnaire administered on them by a male medical doctor. Anthropometric measurements were conducted and samples were collected for laboratory investigations.

The prevalence of erectile dysfunction was $73.9 \%$. Erectile dysfunction was associated with higher age $(p=0.009)$, higher systolic blood pressure $(p=0.009)$ and being on hypertensive drugs $(p=0.007)$. The proportion of diabetic patients with higher glycosylated haemoglobin was higher among patients with erectile dysfunction ( $p=0.020$ ).

This study shows high prevalence of erectile dysfunction in diabetes mellitus patients attending Parirenyatwa outpatient clinic. Erectile dysfunction was associated with higher age, higher systolic blood pressure and being on antihypertensive drugs. This study shows the need of consistent screening of erectile dysfunction among diabetic patients for early detection, treatment and prevention. There is also need for a large national study to confirm this prevalence and the associated factors.
\end{abstract}

Keywords: erectile dysfunction, diabetes mellitus.

\section{Introduction}

Erectile dysfunction has been identified to be a major problem amongst diabetes mellitus patients (Mutagaywa et al. 2014). Erectile dysfunction has been defined as the inability to achieve and maintain an erection which is sufficient to permit satisfactory sexual intercourse (Mutagaywa et al. 2014) (Hackett 2009). The causes of erectile dysfunction are classified into organic or psychogenic. Organic causes of sexual dysfunction are drug induced, traumatic/post-surgical, vascular, endocrine induced and neurological. Whilst psychogenic causes include relationship problems, performance anxiety and depression (Mutagaywa et al. 2014).

The main risk factors of erectile dysfunction amongst diabetes mellitus patients are neuropathy, vascular insufficiency, poor glycaemic control, hypertension, low testosterone levels and life style which include smoking, alcohol and inactivity. The prevalence of erectile dysfunction increases with age (Mutagaywa et al. 2014). Sexual problems are not usually discussed with doctors due to embarrassment and lack of understanding of the condition thus the patients suffer silently. The clinicians and the patients all have difficulty bringing up sexual matters (Malavige et al. 2014).

The prevalence of erectile dysfunction among diabetes mellitus patients ranges from 35 to $90 \%$ compared to $26 \%$ in the general population. In a study carried out on diabetic patients attending diabetic clinic at Muhimbili National Hospital Tanzania between May and December 2011 the prevalence of 
DOI: $10.21522 / \mathrm{TIJPH} .2013 .06 .02 . A r t 009$

ISSN: $2520-3134$

erectile dysfunction was reported to be $55.1 \%$ of which $12.8 \%$ had mild dysfunction, $11.5 \%$ moderate and 27.5\% severe dysfunction (Mutagaywa et al. 2014). The prevalence of erectile dysfunction and its associated factors in Zimbabwe to our knowledge has not been studied. Thus the study sought to determinate the prevalence of erectile dysfunction and associated factors amongst male diabetes mellitus patients attending the outpatient clinic at Parirenyatwa group of hospitals.

\section{Materials and methods}

The main study, Clinical Biochemical Genetic and Biochemical characteristics associated with the development on nephropathy was a cross sectional study in which 348 patients with diabetes mellitus 18 years and above monitored at Parirenyatwa outpatient clinic were recruited between 23 October 2013 and 09 July 2014. The study was ethically approved by the Joint Research Ethics Committee for the University of Zimbabwe College of Health Sciences and Parirenyatwa Group of Hospitals and the Medical Research Council of Zimbabwe.

All diabetic patients monitored at Parirenyatwa Group of hospitals outpatient clinic were given information on the study. All patients who agreed to participate in the study were asked to give written consent. Information on demography, anthropometric measurements and clinical data and laboratory samples were collected as part of the main study. The male participants had an International Index of Erectile Function (IIEF-5) Questionnaire administered on them by a male medical doctor. Erectile dysfunction scores of 22 to 25 were classified as no erectile dysfunction where as a score of 21 and below were classified as erectile dysfunction (Shi et al. 2014) (Binmoammar et al. 2016).

The body mass index was calculated by dividing weight by the square of the height. A sphygmomanometer was used to measure blood pressure. Neuropathy was diagnosed by the medical doctor using history of neuropathy symptoms, pin prick sensation, vibration perception using a 128 tuning folk, assessment of ankle reflexes and temperature sensation.

The Mindray analyser was calibrated and control samples were analysed before study samples were analysed for total cholesterol, triglycerides, high density lipoprotein cholesterol and glycosylated haemoglobin.

\section{Data analysis}

The STATA version 13 was used for statistical analysis, Descriptive statistic was used. Chi squared was carried out for categorical data and the Student $t$ test for dichotomous and continuous variables in bivariate analysis. Multivariate logistic regression was carried out for adjusted odds predictors of erectile dysfunction. A p value of less than 0.05 were considered statistical significant.

\section{Results}

Out of the 348 diabetes mellitus patients recruited into the study 94 were male. Of the 94 male patients who responded 5.3\% [5/94] could not respond to the questions in the questionnaire due to the fact they were not married or widowed. In this study 73.4\% [69/94] had International Index of Erectile Function (IIEF-5) Questionnaire administered on them. Amongst the 69 diabetic patients 51/69 had erectile dysfunction giving a prevalence of $73.9 \%$. Among the 69 patients, there was one current smoker and 5 patients who indicated they drink alcohol. Of the 5 patients who indicated they drink alcohol 3 had erectile dysfunction. 
Table 1. To show factors associated with erectile dysfunction

\begin{tabular}{|c|c|c|c|}
\hline Characteristics & $\begin{array}{l}\text { Erectile } \\
\text { dysfunction } n= \\
\mathbf{5 1}\end{array}$ & $\begin{array}{l}\text { No erectile } \\
\text { dysfunction } n= \\
18\end{array}$ & p Value \\
\hline Age/Years & $60.4 \pm 14.5$ & $49.6 \pm 15.3$ & 0.009 \\
\hline Body mass index $/ \mathrm{Kg} / \mathrm{m}^{2}$ & $24.5 \pm 4.7$ & $25.1 \pm 4.9$ & 0.677 \\
\hline $\begin{array}{l}\text { Systolic blood } \\
\text { pressure/mmHg }\end{array}$ & $155.6 \pm 25.5$ & $138.6 \pm 13.5$ & 0.009 \\
\hline $\begin{array}{l}\text { Diastolic blood } \\
\text { pressure } / \mathrm{mmHg}\end{array}$ & $83.8 \pm 11.9$ & $78.2 \pm 11.3$ & 0.083 \\
\hline $\begin{array}{l}\text { On hypertensive drugs } \\
\text { Yes } \\
\text { No }\end{array}$ & $\begin{array}{l}40 \\
11\end{array}$ & $\begin{array}{l}8 \\
10\end{array}$ & 0.007 \\
\hline $\begin{array}{l}\text { Neuropathy } \\
\text { Yes } \\
\text { No }\end{array}$ & $\begin{array}{l}23 \\
28\end{array}$ & $\begin{array}{l}7 \\
11\end{array}$ & 0.648 \\
\hline $\begin{array}{l}\text { History of myocardial } \\
\text { infarction } \\
\text { Yes } \\
\text { No }\end{array}$ & $\begin{array}{l}4 \\
47\end{array}$ & $\begin{array}{l}0 \\
18\end{array}$ & 0.566 \\
\hline Total cholesterol $/ \mathrm{mmol} / \mathrm{L}$ & $4.3 \pm 1.5$ & $4.3 \pm 1.5$ & 0.942 \\
\hline Triglycerides $/ \mathrm{mmol} / \mathrm{L}$ & $1.1(0.7-1.6)$ & $1.1(0.6-1.8)$ & 0.633 \\
\hline $\begin{array}{l}\text { High density lipoprotein } \\
\text { cholesterol/mmol/L }\end{array}$ & $1.1 \quad \pm 0.4$ & $1.1 \pm 0.4$ & 0.672 \\
\hline $\begin{array}{l}\text { Glycosylated } \\
\text { haemoglobin/\% }\end{array}$ & $8.4(6.8-11.1)$ & $6.6(5.7-9.0)$ & 0.116 \\
\hline $\begin{array}{l}\text { Glycosylated } \\
\text { haemoglobin } \geq 7 \%\end{array}$ & $38[74.5 \%]$ & $8[44.4 \%]$ & 0.020 \\
\hline
\end{tabular}

Erectile dysfunction was associated with higher age, higher systolic blood pressure and being on hypertensive drugs. The proportion of diabetic patients with higher glycosylated haemoglobin (glycosylated haemoglobin $\geq 7 \%$ ) was higher among patients with erectile dysfunction.

\section{Discussion}

It is important to note that diabetes mellitus has been associated with sexual dysfunction in both men and women. However among the women the evidence of the association of diabetes mellitus and sexual dysfunction is less conclusive even though most studies have reported higher prevalence of female sexual dysfunction in diabetic women when compared with non-diabetic women. In men diabetes mellitus is an established risk factor for sexual dysfunction with a documented threefold increase in risk of erectile dysfunction in diabetes mellitus men comparing to non-diabetes mellitus men (Esposito, Maiorino, and Bellastella 2014). In this study the prevalence of erectile dysfunction was high and more than $55.1 \%$ reported at Muhimbili National Hospital [2011] (Mutagaywa et al. 2014), 56.4\% reported in Benin City Nigeria [2004] (Unadike, Eregie, and Ohwovoriole 2008), 57\% reported in city of Bobo Dioulasso Burkina Fasso [2012] (Kambou et al. 2014) but lower than 95\% reported at Steve Biko Academic Hospital Diabetic Clinic South Africa (Kemp and Rheeder 2015). Similar to this study, a study in diabetic patients in five hospitals in Northern Ethiopia reported a prevalence of 69.9\% (Seid et al. 2017). Furthermore, the prevalence of erectile dysfunction among patients with diabetes mellitus was within the reported prevalence of 35 to $90 \%$ (Binmoammar et al. 2016). Difference in prevalence of erectile dysfunction has been attributed to difference in composition of study population (Mutagaywa et al. 2014), 
DOI: $10.21522 / \mathrm{TIJPH} .2013 .06 .02 . A r t 009$

ISSN: $2520-3134$

sexual disorders are considered personal and private that most patients will not readily discuss them (Unadike, Eregie, and Ohwovoriole 2008). Studies from high income countries report lower prevalence of erectile dysfunction than that in developing countries, this is attributed to the fact that in developed countries diabetes mellitus is detected early and glucose is well controlled hence preventing the development of diabetic complications (Mutagaywa et al. 2014).

The prevalence of erectile dysfunction increases with age. In this study higher age was associated with erectile dysfunction similarly in a study at Muhimbili National Hospital [2011] age was also associated with erectile dysfunction (Mutagaywa et al. 2014).

Hypertension has been associated with the development of erectile dysfunction (Esposito, Maiorino, and Bellastella 2014). In this study being on antihypertensive drugs which is caused by having high blood pressure as well as higher systolic blood pressure were associated with erectile dysfunction. The etiology of erectile dysfunction in hypertensive males is reported to be multifactorial and may be caused by vascular disease, decreased heart capacity, medication and/or other factors such as heavy smoking, psychological issues, obesity and physical inactivity (Salman et al. 2016). Erectile dysfunction has been associated with use of $\beta$-blockers, thiazide diuretics, metformin, antidepressants, statins, fibrates and the drugs used for neuropathic pain such as pregabalin, gabapentin and opiate analgesics (Hackett 2016).

The proportion of diabetic patients with higher glycosylated haemoglobin (glycosylated haemoglobin $\geq 7 \%$ ) was higher among patients with erectile dysfunction compared to patients without erectile dysfunction. However it has been reported that it is not clear whether hyperglycaemia is a risk factor for the development of erectile dysfunction. Some studies have observed association between poor glycaemic control as expressed by elevated levels of glycosylated haemoglobin whist other studied did not report any association (Esposito, Maiorino, and Bellastella 2014). Further research is required to clarify causal link between prolonged hyperglycaemia and erectile dysfunction (Binmoammar et al. 2016).

Erectile dysfunction is a treatable complication of diabetes mellitus with reported success rate of treatment of 95\% (Seid et al. 2017). However erectile dysfunction is reported to be one of most neglected complication of diabetes mellitus (Mofid et al. 2009). Pathophysiology of erectile dysfunction is multifactorial. Normally biological and psychological factors work synchronously leading to an erection. Psychological arousal causes biological cascade that involves parasympathetic activation and consequent nitric oxide release from local endothelial cells. Nitric oxide mediates smooth muscle and vascular relaxation causing increased arterial flow to the penile corpora cavernosa. The increasing blood flow impedes venous return via compression of penile venules, thus maintaining an erection. Erectile dysfunction develop in diabetes mellitus patients due to an interplay of neuropathy, vasculopathy, hypogonadism, endothelial dysfunction and psychological factors (Hackett 2016).

\section{Conclusion}

This study shows high prevalence of erectile dysfunction in diabetes mellitus patients attending Parirenyatwa outpatient clinic. Erectile dysfunction was associated with higher age, higher systolic blood pressure and being on antihypertensive drugs. This study shows the need of consistent screening of erectile dysfunction among diabetic patients for early detection, treatment and prevention. There is also need for a large national study to confirm this prevalence and the associated factors.

\section{References}

[1].Binmoammar, Turki A, Sondus Hassounah, Saad Alsaad, Salman Rawaf, and Azeem Majeed. 2016. "The Impact of Poor Glycaemic Control on the Prevalence of Erectile Dysfunction in Men with Type 2 Diabetes Mellitus: A Systematic Review.” JRSM Open 7 (3): 205427041562260. doi: 10.1177/2054270415622602.

[2].Esposito, Katherine, Maria Ida Maiorino, and Giuseppe Bellastella. 2014. "Diabetes and Sexual Dysfunction: Current Perspectives." Diabetes, Metabolic Syndrome and Obesity: Targets and Therapy, March, 95. doi:10.2147/DMSO.S36455.

[3].Hackett, G. 2009. "The Burden and Extent of Comorbid Conditions in Patients with Erectile Dysfunction." International Journal of Clinical Practice 63 (8): 1205-13. doi:10.1111/j.1742-1241.2009.02088.x. 
[4].Hackett, Geoffrey Ian. 2016. "Erectile Dysfunction, Diabetes and Cardiovascular Risk." British Journal of Diabetes 16 (2): 52. doi:10.15277/bjd.2016.076.

[5].Kambou, Timothée, Cyprien Zaré, Abdoul Karim Paré, Adama Ouattara, Youombèviel Ludovic Somé, and Bakary Gustave Sanon. 2014. "Erectile Dysfunction among Diabetic Men in Two Medical Centers in Burkina Faso: Epidemiological, Diagnosis and Therapeutic Aspects." Advances in Sexual Medicine 04 (01): 1-5. doi:10.4236/asm.2014.41001.

[6].Kemp, T, and P Rheeder. 2015. "The Prevalence and Associations of Erectile Dysfunction in a South African Male Diabetic Urban Population." Journal of Endocrinology, Metabolism and Diabetes of South Africa 20 (3): 13439. doi:10.1080/16089677.2015.1090185.

[7].Malavige, L. S., S. D. Jayaratne, S. T. Kathriarachchi, S. Sivayogan, P. Ranasinghe, and J. C. Levy. 2014. "Erectile Dysfunction Is a Strong Predictor of Poor Quality of Life in Men with Type 2 Diabetes Mellitus." Diabetic Medicine 31 (6): 699-706. doi:10.1111/dme.12412.

[8].Mofid, Alireza, SeyedAhmad Seyedalinaghi, Saeed Zandieh, Tahereh Yazdani, and Sara Jam. 2009. "Prevalence and Risk Factors of Erectile Dysfunction in Iranian Diabetic Men." Acta Medica Iranica 47 (4): 309-14.

[9].Mutagaywa, Reuben Kato, Janeth Lutale, Aboud Muhsin, and Benjamin Anathory Kamala. 2014. "Prevalence of Erectile Dysfunction and Associated Factors among Diabetic Men Attending Diabetic Clinic at Muhimbili National Hospital in Dar-Es-Salaam, Tanzania.” Pan African Medical Journal 17. doi:10.11604/pamj.2014.17.227.2695.

[10]. Salman, Muhammad, Naureen Shehzadi, Muhammad T Khan, Muhammad Islam, Sohail Amjad, Omer Afzal, Sibghat Mansoor, et al. 2016. "Erectile Dysfunction: Prevalence, Risk Factors and Involvement of Antihypertensive Drugs Intervention.” Tropical Journal of Pharmaceutical Research 15 (4): 869. doi:10.4314/tjpr.v15i4.29.

[11]. Seid, Awole, Hadgu Gerensea, Shambel Tarko, Yosef Zenebe, and Rahel Mezemir. 2017. "Prevalence and Determinants of Erectile Dysfunction among Diabetic Patients Attending in Hospitals of Central and Northwestern Zone of Tigray, Northern Ethiopia: A Cross-Sectional Study." BMC Endocrine Disorders 17 (1). doi: 10.1186/s12902-017-0167-5.

[12]. Shi, M-D, J-K Chao, M-C Ma, S-K Chiang, and I-C Chao. 2014. "The Connection between Type 2 Diabetes and Erectile Dysfunction in Taiwanese Aboriginal Males." International Journal of Impotence Research 26 (6): 23540. doi:10.1038/ijir.2014.26.

[13]. Unadike, B. C., A. Eregie, and A. E. Ohwovoriole. 2008. "Prevalence and Types of Sexual Dysfunction among Males with Diabetes in Nigeria." Mera: Diabetes International, 18-20. 